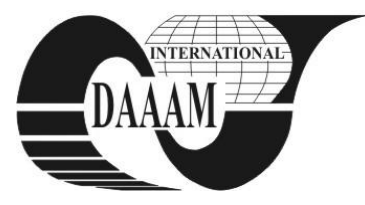

Annals of DAAAM for 2011 \& Proceedings of the 22nd International DAAAM Symposium, Volume 22, No. 1, ISSN 1726-9679 ISBN 978-3-901509-83-4, Editor B. Katalinic, Published by DAAAM International, Vienna, Austria, EU, 2011 Make Harmony between Technology and Nature, and Your Mind will Fly Free as a Bird Annals \& Proceedings of DAAAM International 2011

\title{
THE REAL EQUIPMENT MODELS LABORATORY AND THEIR CONTROL POSSIBILITIES
}

\author{
SYSALA, T[omas] \& NEUMANN, P[etr]
}

\begin{abstract}
This paper describes laboratory models that are used in the educational process at our faculty. Those real equipment models are controlled through the programmable logical controllers (PLC). As a first task step, students have to connect the particular model to a PLC. As a further step, they have to create a program for the model control, and verify the program functionality. The second part is the description of possibilities for the model control
\end{abstract}

Key words: real model, real model control, PLC, education

\section{INTRODUCTION}

Curriculums at our faculty are specialized on applied informatics and technological processes control. Our students attend several different mainly theoretical courses specialized on the control theory, like the Automatic control theory, System simulation, System identification, Measurement and control in technological processes, and other control related subjects.

In relation to that, they pass also through application courses, like Microcomputers and their applications, Programmable logical controllers and many others where they apply their knowledge gained in preceding courses. In those application courses, students need to understand the particular method of measurement. Students also have to be familiar with sensor types for various application areas, like temperature and pressure measurement, speed, power and liquid level measurement (Sysala et al., 2006).

In the PLC course, the teacher specifies both a model to control and a control method as well. Students have to propose the controller version, and they implement it into control software of a PLC then. For the sake of that, they have to be familiar with its programming system and its programming language. Providing the realized application proves functional, students create a visualization project in some SCADA/HMI software.

\section{REAL MODELS}

There are several models in our laboratory for PLC programming education. Among those models are real equipment models and models based on a microcontroller. All models are connected to a PLC and optionally that PLC is connected to a PC.

\subsection{Models based on a microcontroller}

All models from this group look very similar. They consist of a microcontroller board where the program is stored, LED diodes board for an equipment simulation, connector and cable to connect a PLC. A microcontroller program simulates behaviour of real equipment. It reads inputs (outputs from a PLC), and it sets outputs (inputs to PLC) so that the PLC doesn't identify whether the signals were send by a model or by a real equipment (Kohout, 2004).
There is a second board embedding the above mentioned microcontroller board.

Example: A washing machine model - PLC sends a signal "heating", "rotation left or right", "wringing", etc. The model sends back to the PLC water temperature and water level.

There are following microcontroller models at our laboratory:

- washing machine,

- interfluent unit,

- cross-roads,

- autoclave,

- moveable conveyer,

- seven segments LED display for a number representation.

\subsection{Real equipment models}

The second group is a group of real equipment models. Each model is connected to a PLC and we can control all inputs and measure all outputs of the model.

There are the following models at our laboratory:

- elevator model (1 cab, 3 floors),

- railway model,

- small fountain,

- family house model (Dvoracek, 2007),

- ball levitation on a water column model (Vrzal, 2007),

- elevator model (2 cabs, 5 floors) (Vrzal, 2010).

\section{REMOTE CONTROL}

There are several possibilities how to change some parameters for a process control flow stored in PLC memory, or how to present data related to a technological process or PLC memory. Some of them are described hereafter.

\subsection{HMI Panel}

HMI panel - Human Machine Interface panel is the easiest way to change parameters in the PLC. But this way has a disadvantage - we have to be close to the control PLC so that it is not a remote control situation.

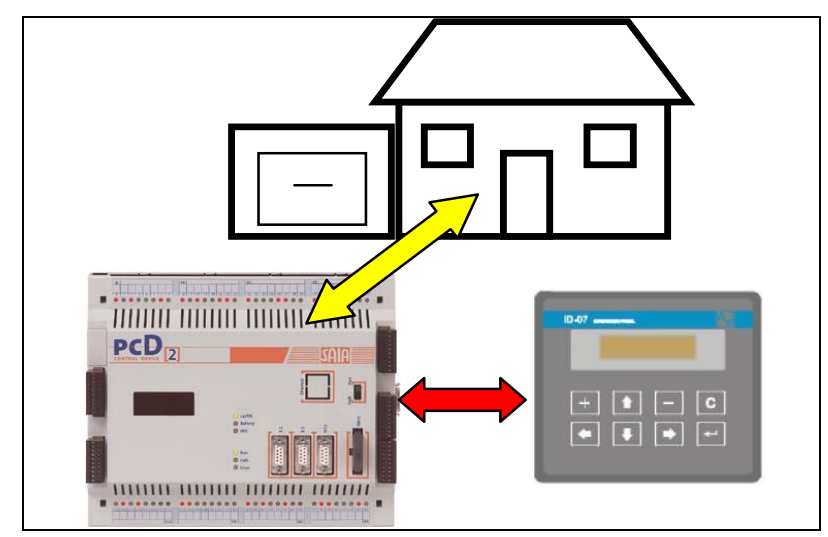

Fig. 1. Model control through HMI panel 


\subsection{RS232, RS485}

The other way is to use common communication via RS232 or RS485. This way is used if PLC has exclusively these types of communication ports. We use this way in situations where we have got older PLCs. A PLC is connected to a personal computer or to another up-to-date PLC type. Through that device, we have access to all inputs and outputs of the first PLC.

\subsection{Internet, Intranet access}

Current data PLC facilitates distributed industry nets establishment. All devices in this net have dedicated addresses so that we can send data to any PLC in that net. If our net is an industry net, we use a bus for communication. There could be used a Profi-Bus, S-Bus, ModBus or other protocol. We mostly use a TCP/IP protocol if we have a PLC connected to the Internet.

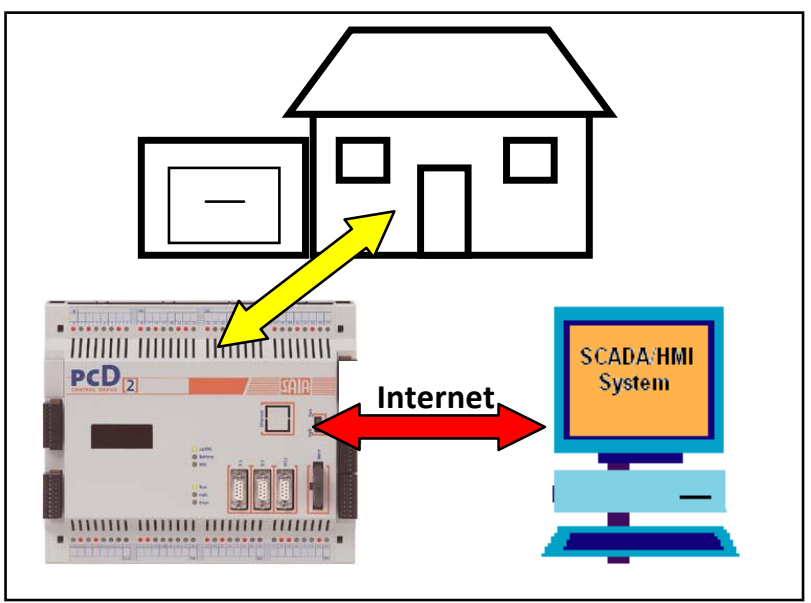

Fig. 2. Remote control via Internet

\subsection{GSM Communication}

If we don't have Intranet or Internet access, and we do not have any possibility to interconnect the controlled process with the control room via a cable, we can use a GSM module installed in the PLC. We can send or receive "Short Messages" (SMS) with that module. It is possible to transfer the parameters of the controlled system, like temperature or water level reading, and we can send SMS with control commands to the heating unit, water pump or other outputs in the PLC (Sobolík, 2007).

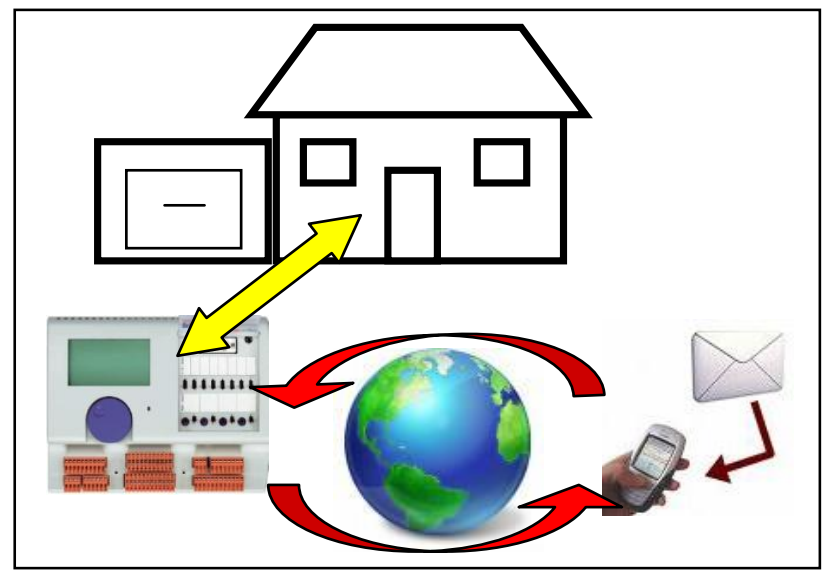

Fig. 3. Remote control via GSM communication

We have all these described methods of communication between technological process and control room in our laboratory.

\section{CONCLUSIONS}

We have described our laboratory and some models for PLC programming education in this paper. The students learn to program and control real equipment models. They can alternate among remote control via personal computer, via PLC or control through a local computer.

The students appreciate their participation in this course because:

- The models look very similar like real equipments.

- Students apply their theoretical knowledge in a real application.

- It is easy to see whether their application is working correct.

- They are well prepared for working with programmable controllers and SCADA/HMI systems at their new job positions in factories, in the future.

We plan a further extension concerning PLC system brands with their original programming environment and other real equipment models in our laboratory. We would like to project that continuous extension and innovation in accordance with the application areas development. Our aim is to keep up our education process with the current technological level in the industrial area.

\section{ACKNOWLEDGMENT}

This work was supported by the Ministry of Education of the Czech Republic under grant MSM 7088352102. This support is very gratefully acknowledged.

\section{REFERENCES:}

Dvoracek, J., (2007). Model domku monitorovaný a ovládaný programovatelným automate (A Family House Model controlled by PLC), diploma work (in czech), Tomas Bata University in Zlin, Faculty of Aplied Informatics

Kohout, L., (2004). Popis jednotlivým modelů rady EDU-mod, (Model EDU-mod description), (in czech), Ing. Ludek Kohout Company, Kutná hora

Sobolik, M., (2007). Nové laboratorní úlohy pro predmèt Programovatelné automaty (New models for course Programmable Controllers), diploma work (in czech), Tomas Bata University in Zlin, Faculty of Aplied Informatics

Sysala, T. (2010). Real equipments laboratory and an elevator model controlled through programmable controller, DAAAM International Vienna, Proceedings of the 21st International DAAAM Symposium "Intelligent Manufacturing \& Automation: Focus on Interdisciplinary Solutions", Vienna, 2010, 0349-0350, ISBN-ISSN 978-3901509-73-5

Sysala, T., Dostál, P. \& Adámek, M., (2006). Monitoring, Measuring and Control Systems for Real Equipment Controlled by PLC in Education, IN: XVIII IMEKO WORLD CONGRESS - Metrology for a Sustainable Development, September, 17 - 22, 2006, Rio de Janeiro, Brazil, p. 9, section TC1

Teco (2006). http://www.tecomat.com - Tecomat FOXTROT, Accessed on: 2010-09-10

Vrzal, O., (2007). Levitace balonku na vodnim sloupci (A ball levitation on the water column), bachelor work (in czech), Tomas Bata University in Zlin, Faculty of Aplied Informatics

Vrzal, O., (2010). Sekvenční řizeni modelu výtahu programovatelným automatem (Sequence control of elevator model by programmable logic controller), diploma work (in czech), Tomas Bata University in Zlin, Faculty of Aplied Informatics 